\title{
Modelling of Twin Rotor Axial Flux Induction Machine and its Application as Differential in Electrical Vehicles
}

\author{
V. Ramesh Babu ${ }^{1}$, Dr.M.P.Soni ${ }^{2}$ \\ Associate Professor, EEE Department, VNRVJIET, Hyderabad, India ${ }^{1}$ \\ Former Professor, EEE Department, MJ college of Engineering \& Technology, Hyderabad, India ${ }^{2}$
}

\begin{abstract}
This paper proposes the modelling of Single Air gap Axial Flux Induction Machine and it is extended to Twin Rotor Axial Flux Induction Machine. It is also proposed to use a Twin Rotor Axial Flux induction Machine as a replacement for existing conventional mechanical differential. The possibility of having shorter axial length and two independent rotors in a single machine favors for above application. These motors are used as wheel motors and this also becomes one credential for using them in electric vehicle applications. Furthermore it is compact and has high power density. The present work is simulated in MATLAB environment.
\end{abstract}

Keywords: Axial flux Induction machine, TRAFIM, modelling, Differential, MAT LAB

\section{INTRODUCTION}

Based on the flux direction in the air gap, electromechanical energy conversion machines are classified into Radial Flux Machines and Axial Flux Machines. The working principle involved in both the axial flux and radial flux machine are same but differs in its construction. In conventional radial flux machines the conductors are placed in parallel and the direction of air gap flux is radial to the shaft axis where as in the axial flux machines the conductors are placed in radial to the shaft and air gap flux is parallel to the shaft.

The earliest machines were AFMs though they were replaced by RFM after a relatively short period of time. In 1821, Faraday invented a primitive disc motor which was in the form of an AFM. However, since 1837, when Davenport claimed the first patent for a RFM, it became the accepted configuration for electrical machines. Since 1980 the applicability of axial flux machines to low-speed, direct-drive electrical drive applications has been studied.

\section{A. Limitations of Radial flux machines}

- Bottle - Neck for the flux path at the root of the rotor slot.

* Cooling Problem.

* In efficient utilization of Rotor Core.

* Long motor length is required because the torque is produced at a fixed air-gap diameter which is effectively smaller than the axial field motor where torque producing diameter grows radially for a fixed air-gap length.

These Limitations cannot be conveniently employed unless there is an alteration in the geometry of the RF machine which leads to a AF machine.

\section{$B$.Advantages of Axial flux machines}

* Cooling is improved

* Large axial length is not required for the production of high torque.

* Tooth flux density is constant.

- Efficient utilization of rotor core

* At a time it can be operated at different speeds with multi air gap topology.

In axial flux machines the stator has ring structure and rotor is disc shaped. The radial length from the stator inner radius to the outer radius is the active part to produce the torque and the axial length is dependent on the 


\section{International Journal of Innovative Research in Electrical, Electronics, Instrumentation and Control Engineering}

\section{ISO 3297:2007 Certified}

Vol. 5, Issue 5, May 2017

proper yoke design of the stator and the rotor i.e., the flux density in the stator and rotor yokes. Though the number of poles increases the active radial part of the machine remains unchanged and the axial length depends on the flux density in stator and rotor yokes. When the ratio of motor overall length to motor external diameter $>1$ then radial flux type is preferred and when it is $<0.3$ axial flux type machine is preferred. Thus the axial flux machine has the flexibility in having higher pole number which let the machine to be an attractive alternative for the low speed applications. Furthermore it has high efficiency, high power and torque densities and low rotor losses.

Fig.1 shows the configurations of a conventional and an axial-field machine. For the conventional machine, the main dimensions are the air gap diameter and the effective length while for the axial-field machine the main dimensions are the outer and inner diameters.

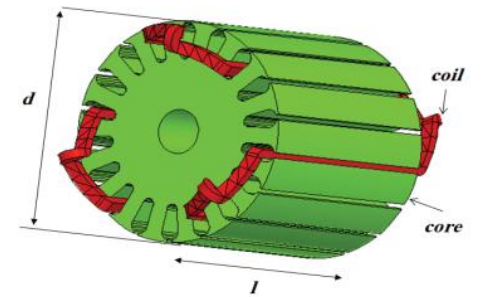

Fig. 1a Radial Flux Machine

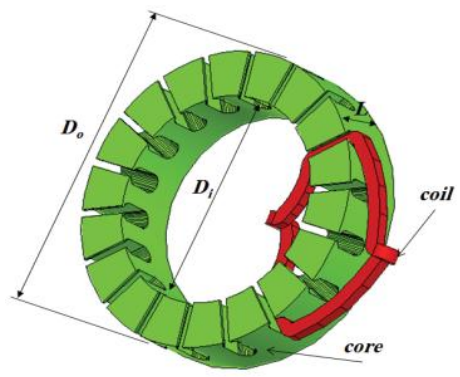

Fig. 1b Axial Flux Machine

Usually these machines can have single or multiple air gaps. The multiple air gap axial flux machines have $\mathrm{N}$ stators and $\mathrm{N}+1$ rotors for internal stator external rotor [ISER] type machines and $\mathrm{N}+1$ stators and $\mathrm{N}$ rotors for external stator and internal rotor [ESIR] type machines. Because of its higher efficiency ISER type machine is preferred. Based on the flux direction in the stator core the two topologies can be derived from ISER. One is North-North (NN) type topology and the other is North-South (NS) type topology. Furthermore these topologies are classified into Slotted type and Non Slotted type. In Non-Slotted type axial flux machine there is only NN type topology which consists of stator with tape wound iron core and windings wrapped around the core with back to back connections where as in Slotted type axial flux machine there are both NN type and NS type topologies.

Based on the above classification different types of permanent magnet synchronous machines and induction machines are derived. Axial flux Induction [AFI] machines are of slotted type. They can be either single air gap or multiple air gaps. In single stator double rotor type structure the rotors can have (i) Two independent shafts driving two different loads and hence two different speeds can be obtained at a time. (ii) Two rotors can share the same shaft enhancing the torque/power output. Furthermore two different topologies are derived from slotted type based on the direction of main flux in the stator core as discussed earlier called Slotted NN-type AFI machine and Slotted NS-type AFI machine which are illustrated in the Fig.2.
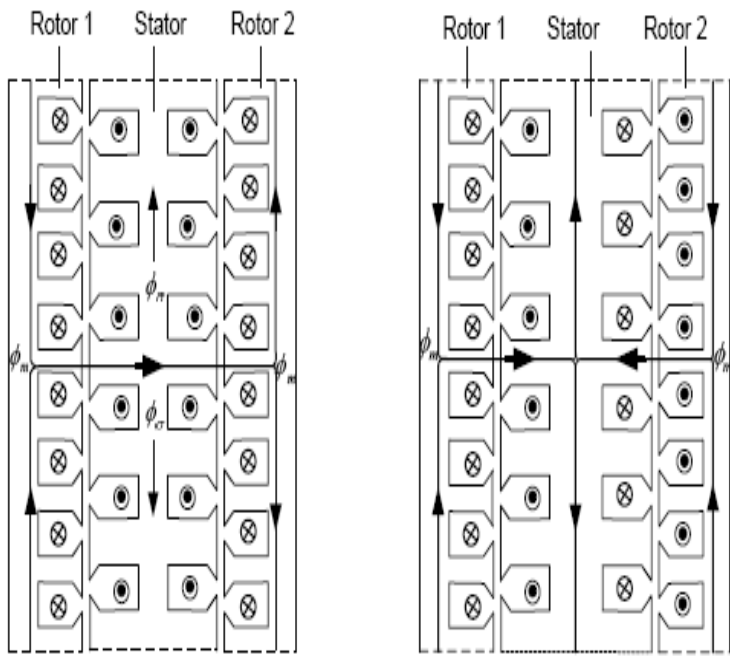

Fig. 2 NS Topology and NN Topology 


\section{MODELLING OF AXIAL FLUX INDUCTION MACHINES}

\section{A. Modelling of Single Air gap Axial flux Induction machine}

The single air gap axial flux induction machine consists of single stator and rotor. The equations which describe the performance of an induction machine are independent of magnetic flux direction in the air gap. The system equations of an axial flux induction machine are given below in the matrix notation.

$$
\left[\begin{array}{l}
{\left[V_{s}\right]} \\
{\left[V_{r}\right]}
\end{array}\right]=\left[\begin{array}{cc}
{\left[R_{s}\right]} & 0 \\
0 & {\left[R_{r}\right]}
\end{array}\right]\left[\begin{array}{l}
{\left[I_{s}\right]} \\
{\left[I_{r}\right]}
\end{array}\right]+p\left[\begin{array}{cc}
{\left[L_{s}\right]} & {\left[L_{s r}\right]} \\
{\left[L_{r s}\right]} & {\left[L_{r}\right]}
\end{array}\right]\left[\begin{array}{l}
{\left[I_{s}\right]} \\
{\left[I_{r}\right]}
\end{array}\right]
$$

The above equation is in the form of

$$
[V]=[R][I]+p[L][I]
$$

The generalized D-Q axes models are used for analyses of machines. Any particular reference frame model can be derived by substituting the appropriate frame speed and position in the generalized reference model. Reference frames rotating at an arbitrary speed are called arbitrary reference frames and other frames are particular cases of this arbitrary reference frame. System equations in arbitrary reference frame can be represented in the matrix notation as

$$
\left[V_{d q s r}\right]=[R]\left[I_{d q s r}\right]+p[L]\left[I_{d q s r}\right]
$$

$[R]=\left[\begin{array}{cccc}R_{s} & -w_{s} L_{s} & 0 & -w_{s} L_{m} \\ w_{s} L_{s} & R_{s} & w_{s} L_{m} & 0 \\ 0 & -\left(w_{s}-w_{r}\right) L_{m} & R_{r} & -\left(w_{s}-w_{r}\right) L_{m} \\ \left(w_{s}-w_{r}\right) L_{m} & 0 & \left(w_{s}-w_{r}\right) L_{r} & R_{r}\end{array}\right]$

$$
[L]=\left[\begin{array}{cccc}
L_{s} & 0 & L_{m} & 0 \\
0 & L_{s} & 0 & L_{m} \\
L_{m} & 0 & L_{r} & 0 \\
0 & L_{m} & 0 & L_{r}
\end{array}\right]
$$

Where " $p$ " represents the differential operator.

The transformation is done into synchronously rotating reference frame. This model is useful where the variables in the steady state need to be DC quantities. Some high performance control schemes use this model to estimate the control inputs. This model facilitates the simulation of vector control methods of induction motor. In synchronously rotating reference frame model, the speed of the reference frame is $\omega$. And equation (3) can be represented in a state variable form as

$$
\frac{d}{d t}\left[I_{d q s r}\right]=\left[L_{d q s r}\right]^{-1}\left[V_{d q s r}\right]-\left[L_{d q s r}\right]^{-1}[R]\left[I_{d q s r}\right]
$$

The above differential equation is solved by using Runge-kutta method in MATLAB to obtain the d-q axis currents of both stator and rotor. The simulation results are shown below.

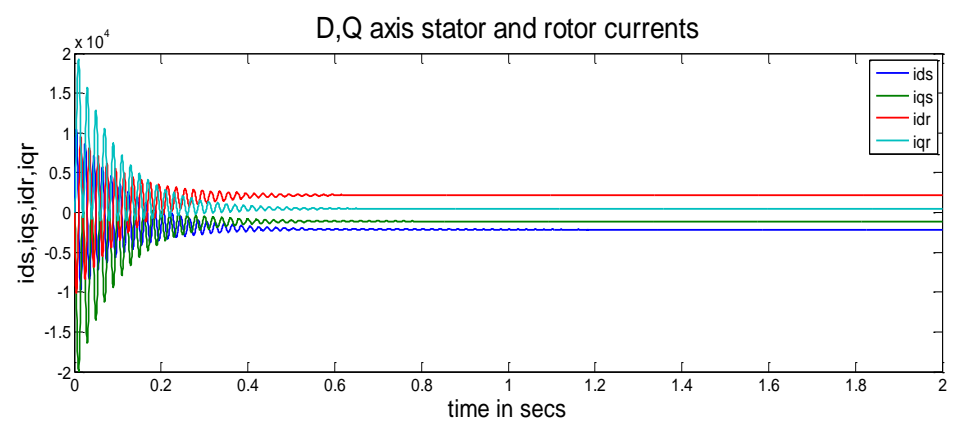

Fig. 3 Stator and rotor currents in synchronous reference frame model 
The electromagnetic torque is obtained by equation (7) and the simulation result is shown in Fig.4.

$$
T_{e}=\frac{3}{2} \frac{p}{2} L_{m}\left\{i_{d r} i_{q s}-i_{d s} i_{q r}\right\}
$$

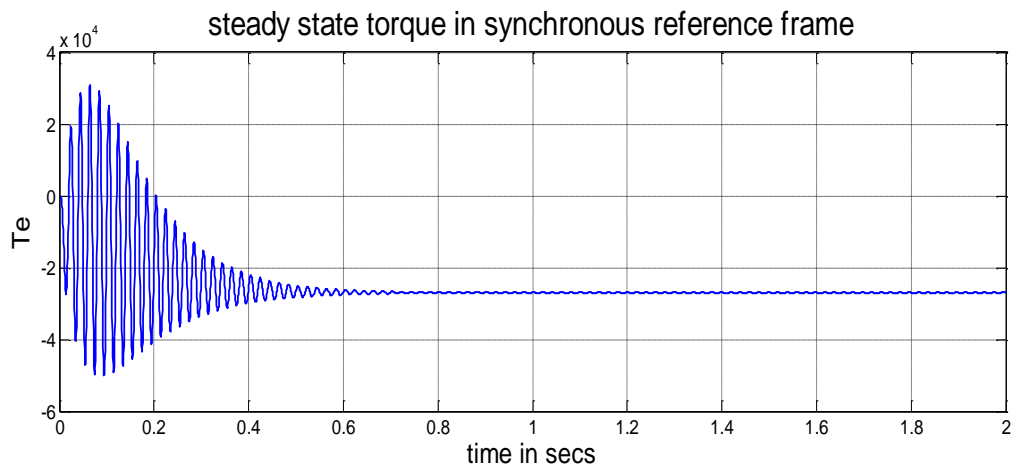

Fig. 4. Steady state torque in synchronous reference frame

\section{B. Modelling of Twin Rotor Axial flux Induction Machine}

The axial flux induction machine consists of single stator sandwiched between two rotors. Since the machine considered here for the modelling is NN type AFIM, the flux path is in parallel with the shaft axis in the air gap and parallel and perpendicular to the shaft axis in the stator core. The $\mathrm{d}-\mathrm{q}$ axis voltage and flux linkage equations of twin rotor AFIM in synchronously rotating reference frame are given below.

$V_{d s}=R_{s} i+p \lambda_{d s}+\omega \lambda_{q s}$

$V_{q s}=R_{s} i+p \lambda_{q s}+\omega \lambda_{d s}$

$V_{d r 1}=R_{r} i_{d r 1}+p \lambda_{d r 1}-\left(\omega-\omega_{r}\right) \lambda_{q r 1}$

$V_{q r 1}=R_{r} i_{q r 1}+p \lambda_{q r 1}+\left(\omega-\omega_{r}\right) \lambda_{d r 1}$

$V_{d r 2}=R_{r} i_{d r 2}+p \lambda_{d r 2}-\left(\omega-\omega_{r}\right) \lambda_{q r 2}$

$V_{q r 2}=R_{r} i_{q r 2}+p \lambda_{q r 2}+\left(\omega-\omega_{r}\right) \lambda_{d r 2}$

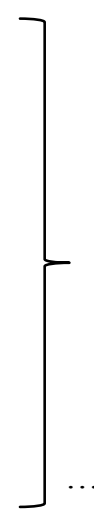

$$
\left.\begin{array}{l}
\lambda_{d s}=L_{s} i_{d s}+L_{m} i_{d r 1}+L_{m} i_{d r 2} \\
\lambda_{q s}=L_{s} i_{q s}+L_{m} i_{q r 1}+L_{m} i_{q r 2} \\
\lambda_{d r 1}=L_{r} i_{d r 1}+L_{m} i_{d s}+L_{m} i_{d r 2} \\
\lambda_{q r 1}=L_{r} i_{q r 1}+L_{m} i_{q s}+L_{m} i_{q r 2} \\
\lambda_{d r 2}=L_{r} i_{d r 2}+L_{m} i_{d s}+L_{m} i_{d r 1} \\
\lambda_{q r 2}=L_{r} i_{q r 2}+L_{m} i_{q s}+L_{m} i_{q r 1}
\end{array}\right\}
$$

The matrix notation of the above set of voltage equations is given below

$$
\left[V_{d q s r 1 r 2}\right]=[R]\left[I_{d q s r 1 r 2}\right]+p[L]\left[I_{d q s r 1 r 2}\right]
$$

Where resistance matrix is and inductance matrix are given below

$$
[R]=\left[\begin{array}{cccccc}
R_{s} & -w L_{s} & 0 & -w L_{m} & 0 & -w L_{m} \\
w L_{s} & R_{s} & w L_{m} & 0 & w L_{m} & 0 \\
0 & -\left(w-w_{r}\right) L_{m} & R_{r} & -\left(w-w_{r}\right) L_{r} & 0 & \left(w-w_{r}\right) L_{m} \\
\left(w-w_{r}\right) L_{m} & 0 & \left(w-w_{r}\right) L_{r} & R_{r} & \left(w-w_{r}\right) L_{m} & 0 \\
0 & -\left(w-w_{r}\right) L_{m} & 0 & -\left(w-w_{r}\right) L_{m} & R_{r} & \left(w-w_{r}\right) L_{r} \\
\left(w-w_{r}\right) L_{m} & 0 & \left(w-w_{r}\right) L_{m} & 0 & \left(w-w_{r}\right) L_{m} & R_{r}
\end{array}\right]
$$




\section{International Journal of Innovative Research in} Electrical, Electronics, Instrumentation and Control Engineering

\section{ISO 3297:2007 Certified}

Vol. 5, Issue 5, May 2017

$[\boldsymbol{L}]=\left[\begin{array}{cccccc}\boldsymbol{L}_{s} & \mathrm{O} & \boldsymbol{L}_{m} & \mathrm{O} & \boldsymbol{L}_{m} & \mathbf{O} \\ \mathbf{O} & \boldsymbol{L}_{s} & \mathrm{O} & \boldsymbol{L}_{m} & \mathbf{O} & \boldsymbol{L}_{m} \\ \boldsymbol{L}_{m} & \mathbf{O} & \boldsymbol{L}_{r} & \mathbf{O} & \boldsymbol{L}_{m} & \mathbf{O} \\ \mathbf{O} & \boldsymbol{L}_{m} & \mathbf{O} & \boldsymbol{L}_{r} & \mathbf{O} & \boldsymbol{L}_{m} \\ \boldsymbol{L}_{m} & \mathbf{O} & \boldsymbol{L}_{m} & \mathbf{O} & \boldsymbol{L}_{r} & \mathbf{O} \\ \mathbf{O} & \boldsymbol{L}_{m} & \mathbf{O} & \boldsymbol{L}_{m} & \mathrm{O} & \boldsymbol{L}_{r}\end{array}\right]$

To obtain the d,q axis currents of stator and rotor, equation (10) must be represented in the state variable form and simulate in the environment of MATLAB. The simulation results are shown below.

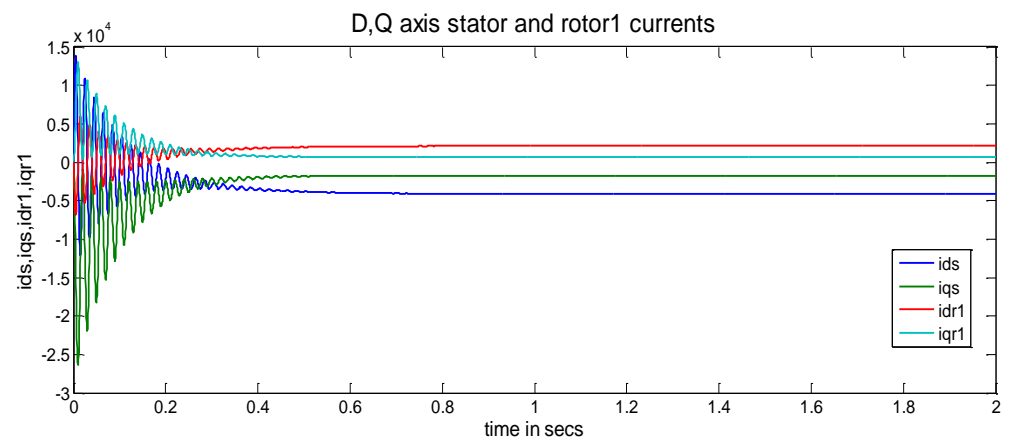

Fig. 5 Stator and rotor1 d,q currents of double airgap Induction machine

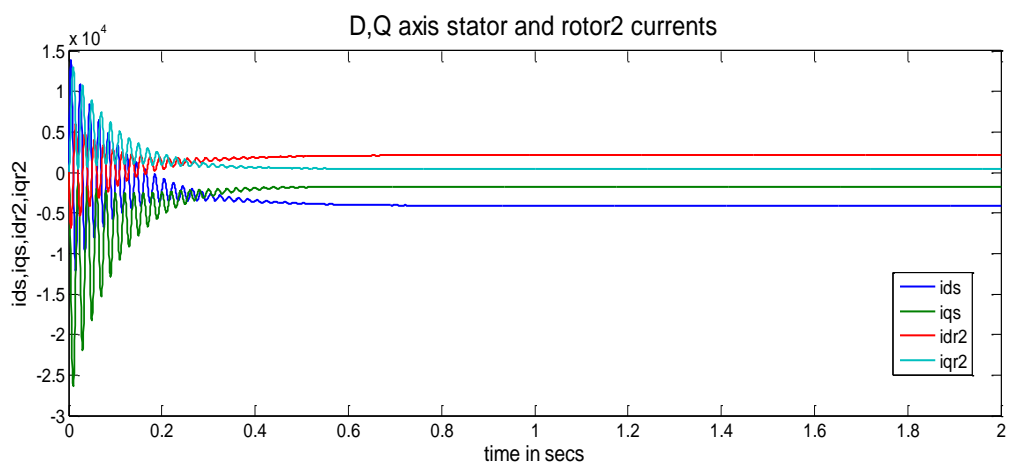

Fig. 6 Stator and rotor 2 d,q currents of double airgap Induction machine

The electromagnetic torque for the twin rotor axial flux induction machine is obtained by simulating equation (13). The simulation result is shown in Fig.7.

$$
T_{e}=\frac{3}{2} \frac{p}{2} L_{m}\left\{\left(i_{d r 1}+i_{d r 2}\right) i_{q s}-i_{d s}\left(i_{q r 1}+i_{q r 2}\right)\right\}
$$

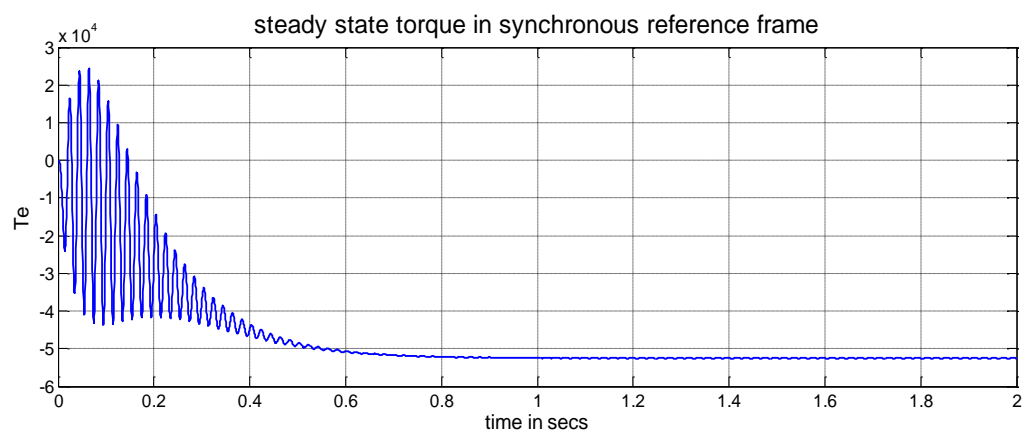

Fig. 7 Steady state torque in synchronous reference frame 


\section{International Journal of Innovative Research in Electrical, Electronics, Instrumentation and Control Engineering}

\section{ISO 3297:2007 Certified}

Vol. 5, Issue 5, May 2017

Therefore the twin rotor axial flux machine is designed and torque corresponding to the rotors is obtained and this lets to investigate the "differential operation in electrical hybrid vehicles" and the torque is found to be doubled than with single rotor. And this analysis lets to investigate on the possibility of replacing the RFIG in the VSWECS with the medium speed TRAFIG so as to reduce the gear box ratio and enhance the power output in "wind energy conversion systems".

\section{III.APPLICATION OF AXIAL FLUX INDUCTION MACHINE AS DIFFERENTIAL IN ELECTRIC VEHICLES}

The problems associated with vehicle emissions have long been a cause for concern, partly due to airborne pollutants, and more recently relating to climate change due to greenhouse gas emissions. According to the US Environmental Protection Agency (EPA), in addition to up to $40 \%$ of greenhouse gas emissions, conventional Internal Combustion Engine (ICE) vehicles contribute 40-50\% of ozone, 80-90\% of carbon monoxide and 50-60\% of air toxins found in urban areas and with vehicle numbers forecast to increase from 700 million to 2.5 billion in the next half century, the need for sustainable transport solutions is clear. So recent years have seen a surge of interest in zero emission transport solutions. The leading contender to replace petrol powered vehicles at present is Battery-powered Electric Vehicles (BEVs), since they are the most efficient solution which can be powered (recharged) entirely from renewable energy sources.

\section{A. Working of a TRAFIM as a Differential}

For electric vehicle applications, wheels motor drives represented a new attractive possible solution for their lightness and compactness. The wheels are directly driven by the electric motor and the gears are not necessary anymore. Because axial flux motors can find their advantageous applications in the low speed, high torque electrical drives. For axial flux motor applied in electric vehicle must be realized: high power/weight and torque/weight ratio, high efficiency and suitable shape to match the constrains space. Twin rotor axial flux induction motor has one stator core with two polyphase windings and two rotors with two different shafts which may rotate independently. All the three magnetic cores (the stator and the two rotors) are in the form of discs with slots for the stator windings and the rotor cages. The machine can be classified as a twin rotor axial flux motor.

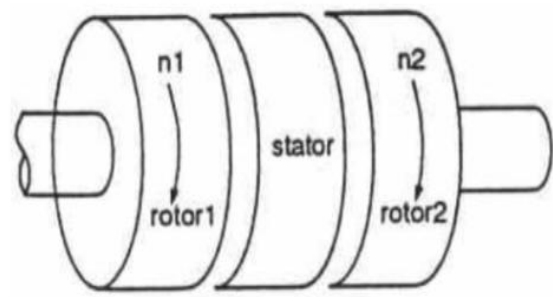

Fig. 8 Two independent rotors driving two different speeds

In simple terms, the machine operates as follows. When the vehicle is steered straight ahead, both driving wheels run at the same speed, and therefore at the same slip. Conditions in the machine are symmetrical and both rotors produce equal armature reaction. Thus all flux, except leakage, linking the stator windings, also links each rotor winding. No flux passes around the yoke of the stator. Both rotors produce the same torque.

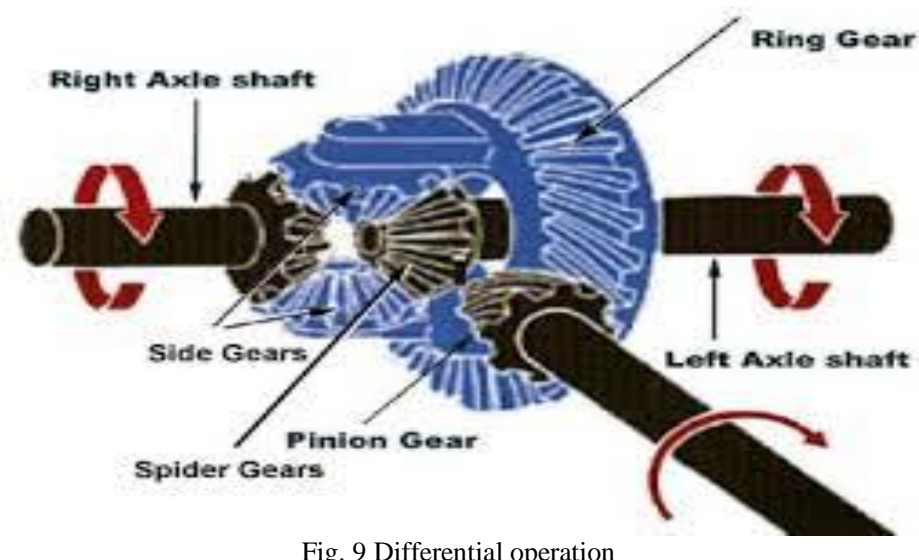

Fig. 9 Differential operation 


\section{International Journal of Innovative Research in Electrical, Electronics, Instrumentation and Control Engineering}

\section{ISO 3297:2007 Certified}

Vol. 5, Issue 5, May 2017

When the vehicles enter a curve, the inner wheel reduced speed and increases slip whereas the outer wheel increases speed and reduced slip. Therefore the armature reaction from the slower rotor exceeds that from the faster rotor. The same total flux linkage is maintained at the stator winding and the net is that the flux linking the low speed rotor is reduced while that linking the high speed rotor is increased. The redistribution of the flux tends to keep the rotor torques balanced. The difference in the fluxes passes around the stator yoke. As the radius of the curve followed by the vehicle is reduced, this process Continues and flux in the stator yoke builds up to the point of saturation. Up to this point, the machine behaves like two machines in series. After this point, saturation limits the flux which can pass around the stator core, and therefore limits the amount by which the rotor flux linkages can differ. These rotor fluxes are then more or less fixed, and the machine starts to take on the characteristics of two machines in parallel connection. This machine is designed to make use of the magnetic saturation of electric steels. Additionally, as results of the disc geometry, saturation will naturally occur in areas of the machine other than the stator yoke. The rotor yokes may saturate, especially at the outer radius, and the teeth of the rotor and stator will saturate, especially at the inner radius.

1) Modelling: If the machine is used for the propulsion of the wheels of an electrical vehicle and is operated along a straight path then the two cage rotors rotate at same speed of the vehicle. When the two rotor speeds are equal, then there is complete balance between the two air gaps of the machine and the two cage rotors share the same amount of the power delivered at the machine input terminals. In this case the speed of the cage rotors is only related to the total electromagnetic torque by

$$
\begin{aligned}
& T_{e 1}-\left(T_{L}+d T\right)=J p \omega_{r 1}+B \omega_{r 1} \\
& T_{e 2}-\left(T_{L}-d T\right)=J p \omega_{r 2}+B \omega_{r 2}
\end{aligned}
$$

Where $\mathrm{T}_{\mathrm{L}}$ is the overall load torque at the axels of the wheels.

Whenever the vehicle enters a curved path the vehicle wheels are forced to rotate at different speeds with respect to the other, and this speed differential action exerted on the vehicle wheels results in a slip constraint for the machine cage rotors. Whenever the vehicle propelled by the machine moves along a curved path, if $T e$ is the average torque related to the machine, the curve trajectory constraints the cage rotor driving the inner wheel to operate with a torque $T e+\Delta T l$ whereas the cage rotor driving outer wheel must rotate with the torque of $T e-\Delta T l$. The differential torque $\Delta T l$ is mainly determined by the turning ratio.

Representing these equations in matrix notation

$$
\left[\begin{array}{c}
T_{e 1}-\left(T_{L}+d T\right) \\
T_{e 2}-\left(T_{L}-d T\right)
\end{array}\right]=J p\left[\begin{array}{c}
\omega_{r 1} \\
\omega_{r 2}
\end{array}\right]+B\left[\begin{array}{c}
\omega_{r 1} \\
\omega_{r 2}
\end{array}\right]
$$

Combining these equation with voltage equations of the axial flux induction motor matrix notation

$$
\left[V_{d q s r 1 r 2}\right]=[R]\left[I_{d q s r 1 r 2}\right]+p[L]\left[I_{d q s r 1 r 2}\right]
$$

Where the $[\mathrm{R}]$ is resistance and $[\mathrm{L}]$ inductance matrices and are given as

$$
[R]=\left[\begin{array}{cccccccc}
R_{s} & -\omega L_{s} & 0 & -\omega L_{m} & 0 & -\omega L_{m} & 0 & 0 \\
\omega L_{s} & R_{s} & \omega L_{m} & 0 & \omega L_{m} & 0 & 0 & 0 \\
0 & -\left(\omega-\omega_{r 1}\right) L_{m} & R_{r} & -\left(\omega-\omega_{r 1}\right) L_{r} & 0 & -\left(\omega-\omega_{r 1}\right) L_{m} & 0 & 0 \\
\left(\omega-\omega_{r 1}\right) L_{m} & 0 & \left(\omega-\omega_{r 1}\right) L_{r} & R_{r} & \left(\omega-\omega_{r 1}\right) L_{m} & 0 & 0 & 0 \\
0 & -\left(\omega-\omega_{r 2}\right) L_{m} & 0 & \left(\omega-\omega_{r 1}\right) L_{m} & R_{r} & \left(\omega-\omega_{r 1}\right) L_{m} & 0 & 0 \\
\left(\omega-\omega_{r 2}\right) L_{m} & 0 & \left(\omega-\omega_{r 2}\right) L_{m} & 0 & \left(\omega-\omega_{r 2}\right) L_{r} & R_{r} & 0 & 0 \\
0 & 0 & 0 & 0 & 0 & 0 & B & 0 \\
0 & 0 & 0 & 0 & 0 & 0 & 0 & B
\end{array}\right]
$$




\section{International Journal of Innovative Research in} Electrical, Electronics, Instrumentation and Control Engineering

\section{ISO 3297:2007 Certified}

Vol. 5, Issue 5, May 2017

$$
[L]=\left[\begin{array}{cccccccc}
\boldsymbol{L}_{s} & \mathrm{O} & \boldsymbol{L}_{m} & \mathrm{O} & \boldsymbol{L}_{m} & \mathrm{O} & \mathrm{O} & \mathrm{O} \\
\mathrm{O} & \boldsymbol{L}_{s} & \mathrm{O} & \boldsymbol{L}_{m} & \mathrm{O} & \boldsymbol{L}_{m} & \mathrm{O} & \mathrm{O} \\
\boldsymbol{L}_{m} & \mathrm{O} & \boldsymbol{L}_{r} & \mathrm{O} & \boldsymbol{L}_{m} & \mathrm{O} & \mathrm{O} & \mathrm{O} \\
\mathrm{O} & \boldsymbol{L}_{m} & \mathrm{O} & \boldsymbol{L}_{r} & \mathrm{O} & \boldsymbol{L}_{m} & \mathrm{O} & \mathrm{O} \\
\boldsymbol{L}_{m} & \mathrm{O} & \boldsymbol{L}_{m} & \mathrm{O} & \boldsymbol{L}_{r} & \mathrm{O} & \mathrm{O} & \mathrm{O} \\
\mathrm{O} & \boldsymbol{L}_{m} & \mathrm{O} & \boldsymbol{L}_{m} & \mathrm{O} & \boldsymbol{L}_{r} & \mathrm{O} & \mathrm{O} \\
\mathrm{O} & \mathrm{O} & \mathrm{O} & \mathrm{O} & \mathrm{O} & \mathrm{O} & \boldsymbol{J} & \mathrm{O} \\
\mathrm{O} & \mathrm{O} & \mathrm{O} & \mathrm{O} & \mathrm{O} & \mathrm{O} & \mathrm{O} & \boldsymbol{J}
\end{array}\right]
$$

Where B and J represents Frictional Coefficient and Moment of Inertia and these values taken as 0.002 and 0.265 respectively. To obtain the behavioural response of the Twin Rotor Axial flux Induction Machine as Differential, the combined voltage and torque equations must be represented in state variable form and simulate in the environment of MAT-LAB. The simulation results show the design of the Twin Rotor Axial flux Induction Machine (TRAFIM) as a Differential in Electric vehicle and it corresponding speed, slip and torque variations.

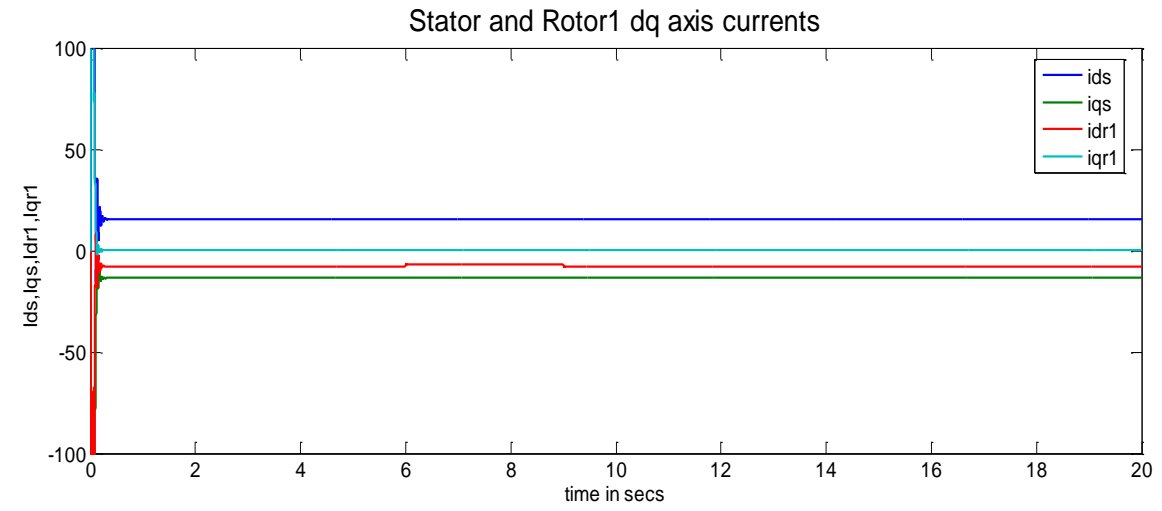

Fig. 10 Stator and rotor1 dq axis currents during differential operation

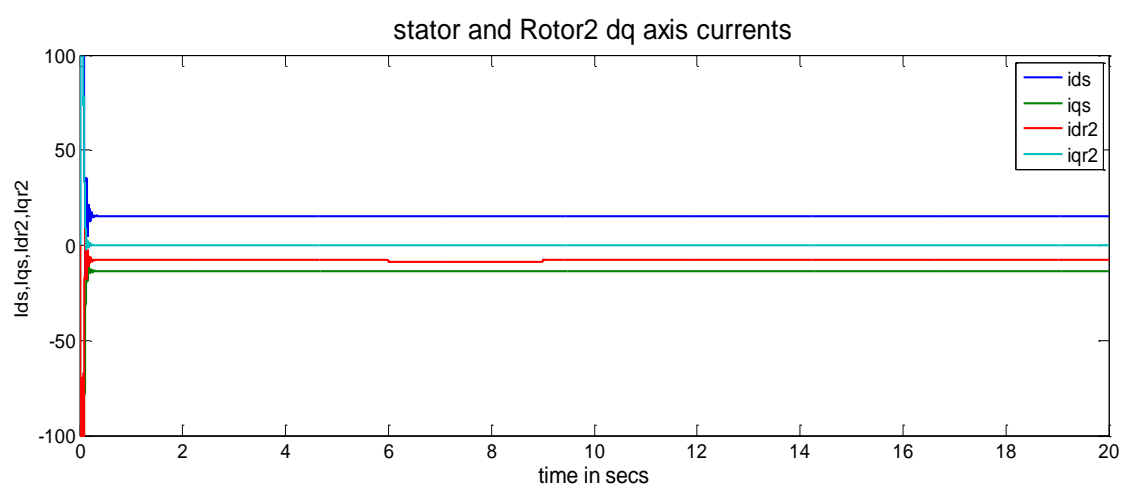

Fig. 11 Stator and rotor 2 dq axis currents during differential operation

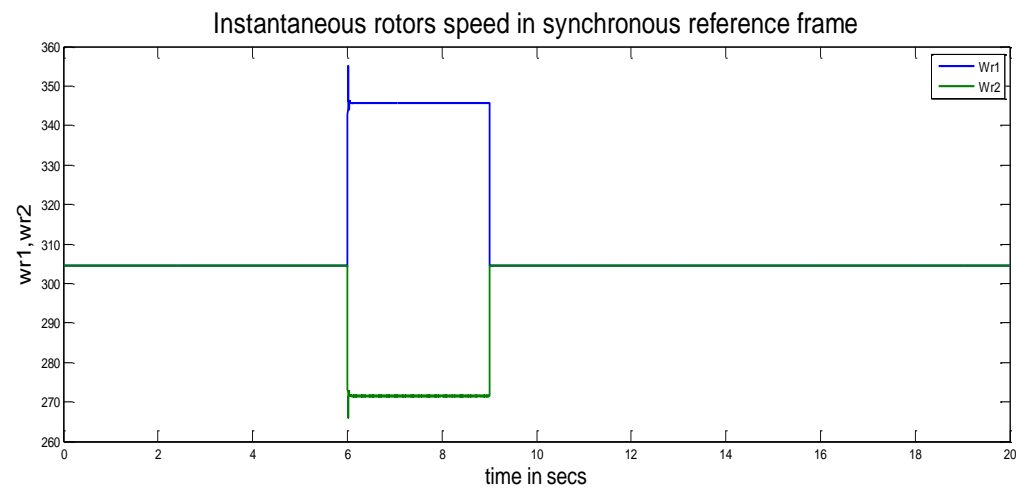

Fig. 12 Speed variations of the rotor1\&rotor2 during differential operation 


\section{ISO 3297:2007 Certified}

Vol. 5, Issue 5, May 2017

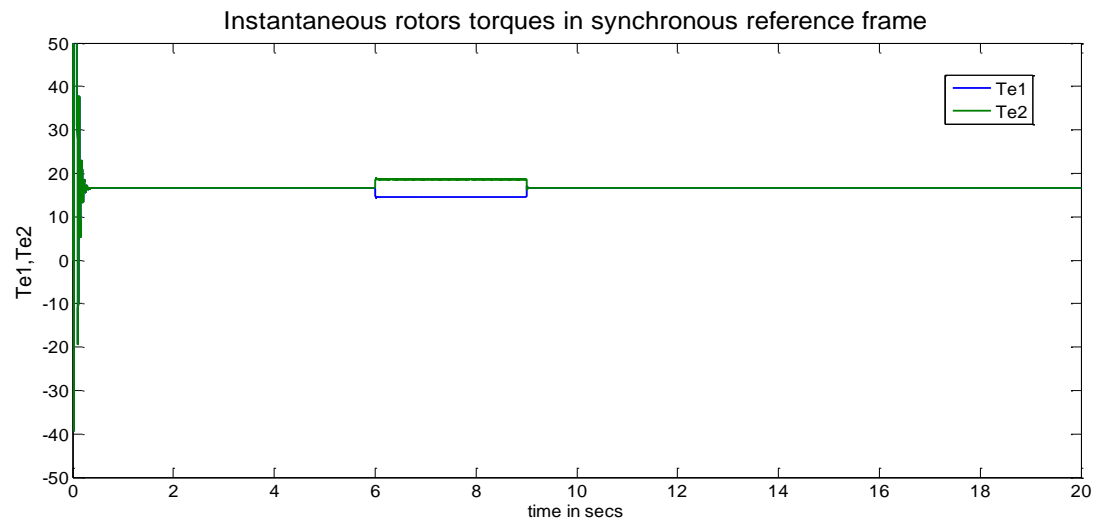

Fig. 13 Torque variations of rotor1 and rotor2 during Differential operation

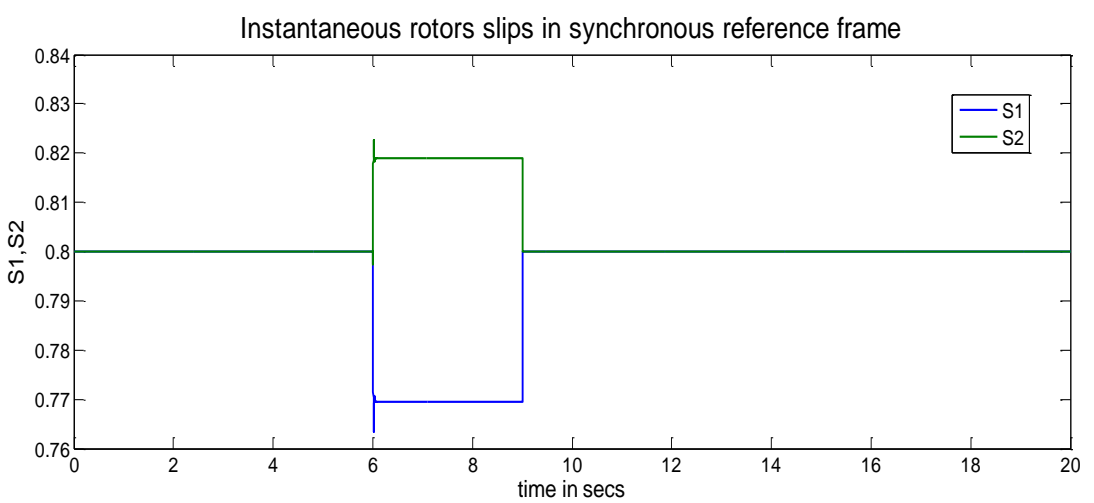

Fig. 14 Slip variations of rotor1 and rotor2 during Differential operation

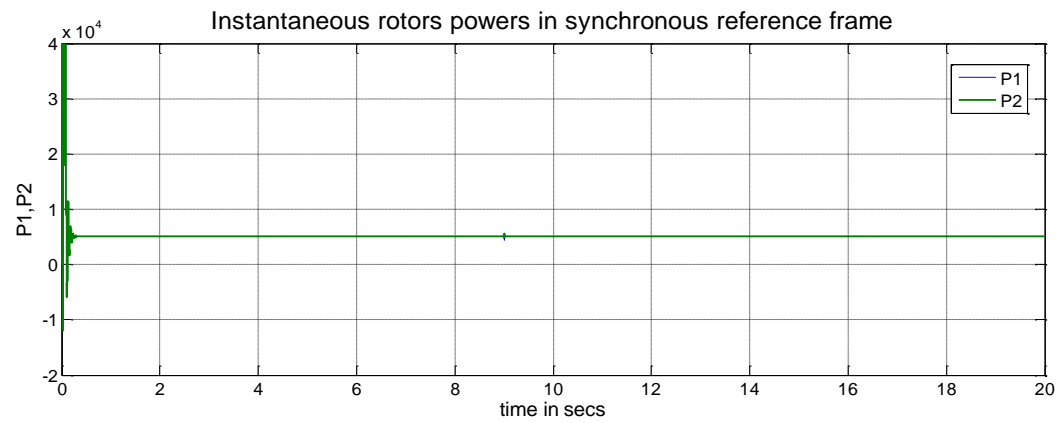

Fig. 15 Constant power throughout the operation of an AFIM

The electric vehicle of the future is expected to be propelled by direct drive wheel motors for more efficient power train. Concerning the electric vehicle application, this paper has presented preliminary results of a study of an original axial flux machine topology which allow one to combine the functions of both the engine and the differential in a single motor drive. The power is maintained constant throughout the operation of a differential.

\section{IV.CONCLUSION}

A detailed literature survey is conducted on Axial flux machines and their credentials are highlighted. The flexibility to have high pole number has lead the Axial flux machines to be used for low speed operations and direct drive applications. A single air-gap Axial flux Induction machine is modelled in MATLAB environment and it is extended for a Twin rotor Axial flux Induction machine case.

The Axial flux machines having shorter axial length are favourable choice for Electric vehicles. These machines provide propulsion by directly connected to wheels and increase the power transfer efficiency. Hence these are also called as wheel motors. The TRAFIM is used as differential in Electric vehicle and preliminary results are presented. The power is assumed to be constant throughout the operation. 
IJIREEICE

\section{International Journal of Innovative Research in Electrical, Electronics, Instrumentation and Control Engineering}

\section{ISO 3297:2007 Certified}

Vol. 5, Issue 5, May 2017

TABLE I

Parameters of AXial FluX Induction Machine

\begin{tabular}{|l|lc|}
\hline Stator Resistance & 1.102 & $\mathrm{~m} \Omega$ \\
\hline Rotor Resistance & 1.497 & $\mathrm{~m} \Omega$ \\
\hline Stator Leakage Inductance & 0.0649 & $\mathrm{mH}$ \\
\hline Stator Magnetizing inductance & 2.1346 & $\mathrm{mH}$ \\
\hline Stator Self Inductance & 2.1995 & $\mathrm{mH}$ \\
\hline Rotor Leakage Inductance & 0.0649 & $\mathrm{mH}$ \\
\hline Rotor Magnetizing Inductance & 2.1346 & $\mathrm{mH}$ \\
\hline Rotor Self Inductance & 2.1995 & $\mathrm{mH}$ \\
\hline Stator-Rotor Mutual inductance & 2.1346 & $\mathrm{mH}$ \\
\hline
\end{tabular}

\section{REFERENCES}

[1] Zahra NASIRI-GHEIDARI, Hamid LESANI, University of Tehran, "A Survey on Axial Flux Induction Motors" PRZEGLĄD ELEKTROTECHNICZNY (Electrical Review), ISSN 0033-2097, R. 88 NR 2/2012.

[2] V. Ramesh Babu, Dr. M.P Soni, "A Novel Method of Using Twin-Rotor Axial Flux Induction Machine for Wind Energy Conversion and the Reactive power Compensation by TSC-TCR" International Journal of Emerging Technology and Advanced Engineering (IJETAE) ISSN 22502459, Volume 2, Issue 8, August 2012.

[3] V. Ramesh Babu, M.P Soni, Ch. Manjeera, "Modelling of Axial flux Induction machine with sinusoidal winding distribution" 2012 Annual IEEE India conference (INDICON), 481 at kochi 7-9 December 2012.

[4] W. S. Leung, J.C.C. Chan, “Axial-Field Electrical Machines- Design and Application”, IEEE Transactions on Power Apparatus and Systems, Vol. PAS-99, No. 4, pp. 1679-1685,July/Aug 1980.

[5] M. Valtonen, "Performance Characteristics of an Axial-Flux Solid-Rotor-Core Induction Motor", Ph.d thesis, Lappeenranta University of Technology, Lappeenranta, Finland, 2007.

[6] Zhang C., Tseng K.J. and Nguyen T.D., „Analysis and comparision of axial flux PM synchronous motor and induction motor”, IEEE conference (2010), IPEC2010, 572-577.

[7] D. Platt, PhD, B.H. Smith, PhD, MlEE, “Twin rotor drive for an electric vehicle” IEE PROCEEDINGS-B, Vol. 140, No. 2, MARCH I993.

[8]. Sumita Sinha, Nirmal K Deb, Nikhil Mondal, Sujit k Biswas," The differential induction machine: Theory and performance” Sadhana Vol. 33, Part 5, October 2008, pp. 663-670. (C) Printed in India.

[9] Dr.M.Ramamoorty, „A Short Course on Electrical Machines' published by ERDA, Vadodara, 2006.

[10] P.C.Krause, Oleng Wasynczuk, Scott D. Sudhoff, „Analysis of electric machinery and drive systems ${ }^{\text {ee }}$. Second edition, A John Wiley \& sons, Inc publication, 2004.

[11] Chee Mun Ong, „Dynamic simulation of electric machinery’, Prentice Hall PTR, Upper saddle river, New Jersey, 07458, 1998.

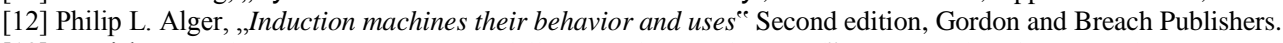

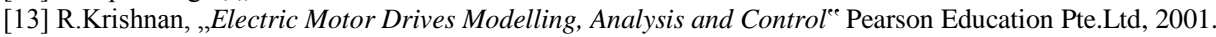

\section{BIOGRAPHY}

V. Ramesh Babu received B.Tech degree from Jawaharlal Nehru Technological University, Hyderabad, India in the year 1998. He obtained the M.Tech degree in power electronics from JNT University, Hyderabad in the year 2004. Currently, he is with VNR Vignana Jyothi Institute of Engineering \& Technology, Hyderabad, as an Associate Professor in Electrical and Electronics Engineering Department. His areas of interests are Electrical Machines and power electronic control of drives.

Dr.M.P.Soni graduated in Electrical Engineering and obtained post-graduation in control systems from Govt. Engineering collage Jabalpur in 1969 \& 1973 respectively. He was awarded Ph.D from I.I.T Bombay in 1977. Dr Soni joined Corporate. R\&D Division of BHEL Hyderabad and retired as Additional General Manager in April 2007. Dr.Soni had distinguished career at BHEL. He headed the Transmission \& Protection lab and guided the Research team for the development of various products. His Ph.D work has been published in IEEE transaction on Nuclear Science. He has also authored a Chapter in the Handbook of Switchgear published by TATA Mc Graw Hill, 2004. Dr. Soni has worked as professor in VNR Vignana Jyothi Institute of Engineering and Technology, and MJ College of Engg and Technology, Hyderabad, India. 